\title{
Jardines y paisajes para un (des)encuentro literario: El Mocho de José Donoso
}

Gardens and Landscapes for a Literary (Mis)Encounter: Jose Donoso's El Mocho

Jardins e paisagens para (des)encontro literário: El Mocho de José Donoso

\section{Sebastián Schoennenbeck}

PONTIFICIA UNIVERSIDAD CATÓLICA DE CHILE, CHILE

Profesor del Departamento de Literatura de la Pontificia Universidad Católica de Chile.

Doctor en Literatura por la Universidad de Chile. Realizó una investigación postdoctoral sobre José Donoso y su apropiación de modelos narrativos anglosajones. Durante los últimos años ha puesto su atención en el paisaje y en su vinculación con la narrativa chilena, dando lugar a ensayos como "Paisaje, nación y representación del sujeto popular. Visiones de un Chile imaginado" y "Un debate sobre paisaje: un camino para su comprensión en Marta Brunet y Mauricio Wacquez". Es autor del libro fosé Donoso: paisajes, rutas y fugas (Orjihk, 2015). Correo electrónico: sschoenn@uc.cl

\section{Daniela Buksdorf}

UNIVERSIDAD ADOLFO IBÁÑEZ Y UNIVERSIDAD FINIS TERRAE, CHILE

Profesora de la Universidad Adolfo Ibáñez y de la Universidad Finis Terrae. Magíster en Literatura Comparada por la Universidad Adolfo Ibáñez y magíster en Literatura Hispanoamericana por la Pontificia Universidad Católica de Chile. Ha publicado artículos como "Enfermedad y desplazamiento, una lectura postcolonial de La edad de hierro de J.M. Coetzee y Mi hermano de Jamaica Kincaid" en revistas académicas como Literatura y Lingüistica (Chile), y "La reescritura como respuesta literaria" en Revista La Palabra (Colombia). Correos electrónicos: d.bukasdorf@uai.cl,dbuksdorfk@uft.edu

\footnotetext{
Artículo de reflexión

Documento accesible en línea desde la siguiente dirección: http://revistas.javeriana.edu.co

Este artículo es resultado del Proyecto Regular FONDECYT n¹150050 "Muerte en el jardín: paisaje y heterotopía en la obra de José Donoso, Mauricio Wacquez y Adolfo Couve". Investigador Responsable: Sebastián Schoennenbeck Grohnert. Ayudante: Daniela Buksdorf.
} 


\section{Resumen}

Al estar ambientada en el pueblo minero de Lota, $E l$ Mocho (1997), novela póstuma del escritor José Donoso, genera puentes intertextuales con la obra de Baldomero Lillo Sub Terra (1904). Ambos autores establecen relaciones espaciales a partir de un esquema vertical que acusa una oposición social. Sin embargo, José Donoso despliega una nueva mirada sobre este contexto minero chileno, asociado a una tradición naturalista. A través del cultivo del paisaje, la novela de José Donoso desplaza metonímicamente la mirada desde la mina hasta el Parque de Lota, alterando así las subjetividades a partir de la variable de clase.

Palabras clave: paisaje; mirada; clase; minas; subjetividad; narrativa; José Donoso; Baldomero Lillo

\section{Abstract}

El Mocho (1997), posthumous novel by the writer José Donoso, was set in Lota miner town and tends intertextual links with Baldomero Lillo's novel Sub Terra (1904). Both writers establish spatial relationships based on a vertical system, revealing social opposition. However, José Donoso displays a new focus on the Chilean context, related to a naturalistic tradition. Through the landscape as a literary resource, Donoso's novel metonymically moves the view from the mine to the Parque de Lota, altering the subjectivities from the social class variable.

Keywords: landscape; look; social class; mine; subjectivity; narrative; José Donoso; Baldomero Lillo

\section{Resumo}

Sendo definido na cidade mineira de Lota, El Mocho (1997), romance póstumo de José Donoso, gera pontes intertextuais com o trabalho de Baldomero Lillo Sub Terra (1904). Ambos os autores estabelecem relações espaciais de um esquema vertical, acusando a oposição social. No entanto, José Donoso apresenta um novo olhar neste contexto mineração chilena associada a uma tradição naturalista. Através do cultivo da paisagem, do romance de José Donoso metonimicamente contemplar mudanças desde a mina até o Parque Lota, alterando subjetividades a partir da variável de classe.

Palavras-chave: paisagem; olhar; classe social; a minha; a subjetividade; a narrativa; José Donoso; Baldomero Lillo

\section{Cómo citar este artículo:}

Schoennenbeck, Sebastián y Daniela Buksdorf. "Jardines y paisajes para un (des)encuentro literario: El Mocho de José Donoso". Cuadernos de Literatura 21.41 (2017): 248-267. https://doi.org/10.11144/Javeriana.cl21-41.jpdl 
No ES CAS UALI DAD que José Donoso (1924-1996), en su novela póstuma $E l$ Mocho (1997), sitúe la historia narrada en el mundo minero de Lota, espacio que ya había sido 'ocupado' literariamente por Baldomero Lillo (1867-1932) con su conjunto de cuentos titulado Sub Terra (1904). Narrada desde diferentes voces, la trama de la novela de José Donoso está compuesta por historias que giran en torno a la explotación minera ubicada en la zona centro sur de Chile. Tanto los nombres de los piques como de los lugares aludidos (Curanilahue, playa de Champeque, Chiguayante, Chivilingo, etc.) pueden ser identificados geográficamente en los mapas del sector. La obra conlleva un conocimiento acucioso del lugar que se explica, en parte, gracias a la visita que el mismo José Donoso realizó a Lota, experiencia que es relatada por Carlos Franz:

En 1980, un hombre pálido, de ojos azulinos y aspecto distraído, merodeó por los piques. Hizo pocas preguntas, pero oyó mucho, como era su estilo. Subió a los barracones de los mineros en lo alto de la bahía. Se paseó por el parque de 14 hectáreas, donde en el siglo XIX los dueños originales —la familia Cousiño - soñaron un impresionante palacio a la vista del mar austral, y de la colina de escoria negra, siempre creciente, que secretaba su mina. (1)

Este viaje, que puede ser considerado como la donné de la novela para utilizar un término muy propio de Henry James, fue también mencionado en la biografía sobre José Donoso, Correr el tupido velo (2009), escrita por su hija Pilar. Si bien la escritura de esta novela será dejada de lado para ser retomada muchos años más tarde, José Donoso registra en sus cuadernos de notas la importancia de visitar el lugar para identificar sus motivos narrativos. Esta información es reproducida en la obra de su hija: "Ya sé: Lota. Hacer otro viaje, volver. Tiene infinitos ingredientes seductores: parque, clase alta, detritus mineral, población minera, violencia política en la población minera, mar, maravilloso muelle viejo y ferruginoso de embarque, desempleo, violencia de la represión del aparato represivo" (273, cursivas del original).

Más allá de un interés anecdótico, la información que arroja Correr el tupido velo revela la función de la mirada en la composición donosiana. Mirar el paisaje de la zona permite evidenciar la novela; es decir: proyectarla como algo que ilusoriamente se ve. Ello explicaría también la exactitud en la referencialidad geográfica, pese a que la novela en cuestión no es necesariamente realista: "Hablé con Concepción para ir a pasar una semana a Lota y ver cómo están las cosas de la realidad por allá, para mi novela. Estoy convencido de que la voy a «ver», literalmente, entera, una vez que vea, de noche, el cerro de Tosca, que es lo que me interesa" (273-274, cursivas del original). 
A diferencia de José Donoso, Baldomero Lillo omite deliberadamente la información toponímica. Sin embargo, las descripciones de las minas carboníferas junto a sus identificaciones populares (por ejemplo, el Chiflón del Diablo) no solo permiten al lector un reconocimiento del entorno geográfico, sino también delatan el contexto histórico del cual Baldomero Lillo fue testigo:

Una nueva etapa, decisiva, en el desarrollo de la industria comienza en 1852 cuando el empresario Matías Cousiño toma las riendas del negocio del carbón, instaurando una dinastía plutocrática que, además del mineral, ha dejado un parque de burla y escándalo por encima de las minas y el derroche de trasplantados en Francia y Europa. (Concha 31-2)

Pese a sus distancias históricas y formales, las coincidencias espaciales que hay entre la novela de José Donoso y los relatos de Baldomero Lillo no se limitan a una referencialidad geográfica explícita en uno e implícita en otro. Por ejemplo, en la obra de Lillo encontramos temas urbanos tales como el conventillo y la prisión (los cuales, según Jaime Concha, serán explorados por la cuentística chilena posterior) así como, en El Mocho, José Donoso presenta motivos afines ya plasmados anteriormente en El lugar sin límites (1966): el prostíbulo de la Japonesita prefigura el burdel de la Bambina, así como el espectáculo circense de este personaje consuma el baile precursor de la Manuela. Del mismo modo, los mitos y leyendas enlazados con un discurso novelesco y la presencia de poderosos señores terratenientes en El Mocho nos recuerdan algunos recursos ya cultivados en El obsceno pájaro de la noche (1970). Sin embargo, los encuentros más evidentes entre los autores aludidos tienen lugar en una representación espacial cuyo esquema está dado por una verticalidad que dispone los diferentes elementos en directa oposición. En ambas obras podemos identificar un abajo y un arriba: el encierro subterráneo de las minas y, por otro lado, la superficie sujeta a múltiples identificaciones. Según Yuri Lotman, esta representación podría adquirir también un significado que va más allá de lo espacial:

Ya a nivel de construcción de modelos supratextual[es], puramente ideológica, el lenguaje de las relaciones espaciales se revela como uno de los medios fundamentales de interpretación de la realidad. Los conceptos «alto-bajo», «derecho-izquierdo», «próximo-lejano», «abierto-cerrado», «delimitadoilimitado», «discreto-continuo» se revelan como material para la construcción de modelos culturales de contenido absolutamente no espacial y adquieren significado: «válido-no válido», «bueno-malo», «propio-ajeno», «accesibleinaccesible», «mortal-inmortal», etcétera. $(271)$ 
La obra de Baldomero Lillo presenta dos polos existenciales: "el de la tierra de arriba y la tierra de abajo, el de la superficie bajo el sol y las cavernas del subsuelo, el de la tierra perdida y la tierra del trabajo vivido como condena" (Concha 41). Por tanto, el interior de la mina es metáfora de infierno, porque supone un castigo sin redención posible tal como Jaime Concha lo destaca en "Lillo y los condenados de la tierra", título del prólogo a la edición de la obra completa del escritor lotino. En el cuento "Juan Fariña", por ejemplo, la mina es "un encierro regido por el temor al Diablo" (63). Las imágenes de la tumba y la prisión también remiten a esta figuración infernal y construyen "una red de sentido que se potencia hasta alcanzar el plano del mito" (6o-61). José Donoso también explora los recursos del discurso mítico, personalizando la mina como una mujer celosa que arrebata la vida de sus mineros al verse amenazada por una presencia femenina. Esta leyenda, popular entre los lugareños, es la explicación que diferentes personajes dan al acontecimiento trágico con el cual la novela comienza: la muerte de los mineros provocada por un derrumbe del pique.

En oposición a las minas situadas en el plano inferior del eje vertical,José Donoso describe los paisajes costeros y un aristocrático ${ }^{1}$ parque cuyo referente histórico es, sin lugar a dudas, el Parque de Lota. En Baldomero Lillo, en cambio, las superficies terrestres son, la mayoría de las veces, reproducciones del alienante espacio subterráneo: "El invierno, el implacable enemigo de los desamparados, que convertía en torrentes los lánguidos arroyuelos, dejaba los campos desolados y yermos" (Lillo, "El Chiflón del Diablo" 138). Sin embargo, el campo que ha perdido toda reminiscencia arcádica es reemplazado en el cuento "El huerto" por un espacio popular de cultivo:

En la huerta que cultivan Rosa y su madre hay un tipo de trabajo femenino al que se le da claro relieve, por el cuidado con que el autor describe los gestos del riego de la muchacha y, por contraste cuando se describe la destrucción de los vegetales plantados... En el cuento se sugiere que pudiera ser un desiderátum general entre los mineros. Este es un trabajo con cosas que germinan, con cosas que dan vida, que brotan libremente de la tierra, una pequeña parcela de utopía para estos seres hundidos en la esclavitud de la mina. (Concha 55)

1 Para un examen de lo que podríamos entender por "élite tradicional" (y que nosotros identificamos con el nombre de "aristocracia"), proponemos revisar los siguientes estudios: Vicuña, Manuel. La belle époque chilena. Santiago: Sudamericana, 2001. Impreso. Sagredo, Rafael. "Élites chilenas del siglo XIX: Historiografía". Cuadernos de Historia 16 (1996): 103-32. Impreso. 
El huerto será descrito como una "anti-mina" (55). De este modo, se resalta el valor de la tierra que, en el cuento "Los inválidos", será la "materia preciosa" (160) que instaura un paisaje nocturno:

Mina, cúpula estrellada, tierra: el ascenso y descenso de la mirada descriptiva se viene a depositar en la palabra "tierra", con toda su ambigüedad. Esta envoltura no es mero paisaje modernista, externo a los dramas que ocurren en las minas, sino parte esencial y constitutiva de la visión. El drama social queda materializado en los planos cósmicos, es parte de una aventura que va más allá de los hombres. (57)

Ahora bien, por medio del engañoso gesto intertextual con Lillo, José Donoso se desliga de una tradición naturalista, desarticulando un modo de representación ilusionado por el valor de la objetividad. ${ }^{2} \mathrm{Al}$ revisitar un lugar ya visitado por la literatura, el autor no garantiza el reconocimiento espacial que padece una fuerte carga histórica vinculada al problema social. Muy por el contrario, se desmarca de la representación de la realidad del minero como resultado de determinaciones naturales, ambientales, políticas e históricas. En otras palabras, la escritura donosiana ejercita una mirada anti-naturalista sobre un contexto cargado por una tradición literaria que cobijó la escritura de Lillo. En efecto, estudiosos tales como Juana Martínez y Hugo Montes han insistido en presentar al autor de Sub Terra como representante de la Generación de 1897, conjunto constituido "por escritores impregnados del realismo naturalista de Zola" (Montes 87), mientras que Patricia Espinoza amplía los efectos discursivos de Sub Terra con respecto al proyecto de "la afirmación de una identidad nacional" (126), asumido por la narrativa criollista-naturalista de las tres primeras décadas del siglo XX. ¿Cuáles son los recursos de composición con los cuales la novela quiebra la fosilizada asociación lectora originada entre las localidades mineras de Lota y la mimesis que Baldomero Lillo cultivó?

$\mathrm{Al}$ aproximarse visual y subjetivamente al espacio geográfico real citado por la ficción,José Donoso exime a sus voces narrativas de la omnisciencia y la objetividad ${ }^{3}$

2 En su estudio sobe la novela Casa Grande de Luis Orrego Luco, Cedomil Goic afirma que el naturalismo abarca "más extensas zonas de la realidad" (87). De este modo, la novela naturalista analiza, desde una observación exacta, los seres, las cosas y la naturaleza, respetando "el encadenamiento lógico de los acontecimientos" (87).

3 C. Goic describirá la narración naturalista de la siguiente manera: "Está claro que esta objetividad del tipo de narración que imita la actitud del científico, su impasibilidad, su impersonalidad, para la observación y el análisis, no debe entenderse como la ausencia del narrador, que constituye un fenómeno contemporáneo ajeno a la experiencia de la novela moderna y del Naturalismo. El narrador presenta una estructura definida y concreta, y un aspecto fundamental de su concreción la constituye su carácter cientificista" (88). 
que Baldomero Lillo, como escritor naturalista, cultivó. Este proceso de subjetivación al cual es sometido el espacio se lleva a cabo por medio de un paisaje en el que se encuentran, en lugar de pastores, mineros. Es posible entonces pensar este paisaje como una inversión del encierro de la mina. ${ }^{4}$ Se trata de un desplazamiento de la mirada que afecta la enunciación narrativa y, consecuentemente, la representación del objeto que originalmente Lillo había llevado a cabo. Por tanto, el espacio original es sometido a una deformación: la mina figura el parque como si este fuese su reflejo polarizado; es decir: se la representa como espacio donosianamente enmascarado. En definitiva, lo que nos propone El Mocho es el reverso de la mentalidad con la cual Baldomero Lillo compuso su artificio. El parque es, por ende, un mundo sustitutorio del espacio minero sujeto a una determinación naturalista. El desplazamiento de la mirada que acaece entre Lillo y Donoso nos recuerda el ejercicio retórico de la metonimia, tropo que "consiste en designar una cosa con el nombre de otra" (Carreter 277): en la novela se designa la mina con el nombre del parque. La relación entablada entre ambos nombres y referentes podría explicarse desde un principio causal (el parque como efecto de la explotación minera), pero también desde una disposición espacial: la mina, lugar subterráneo, es referida a través del espacio verde que yace sobre la superficie. En otras palabras, aquello que está abajo es designado con el nombre de lo que está arriba.

¿Cómo definir el paisaje en el contexto de la narrativa donosiana? Aunque el término paisaje suele definirse desde el ámbito de las artes visuales y, por tanto, como género pictórico ${ }^{5}$, durante los últimos años hemos podido apreciar un conjunto de aproximaciones interdisciplinarias al concepto (como las de Besse, Silvestri, entre otros). ${ }^{6}$ Un elemento común a todas ellas guarda relación con la relevancia del sujeto, puesto que el paisaje no es solo un paraje, sino también una construcción cultural que presenta variaciones históricas. Javier Maderuelo, en

4 Según Adrián Santini, el encierro es un motivo donosiano por excelencia. A su vez, Severo Sarduy habla de una cadena de inversiones con respecto a El lugar sin límites. Ver: Santini, Adrián. Encierro y sustitución en El obsceno pájaro de la noche. Chile: Ril Editores, 2001. Impreso. Sarduy, Severo. "Escritura/Travestismo. Escrito sobre un cuerpo". Obra Completa Tomo II. Buenos Aires: Sudamericana, 1999. 1147-1151. Impreso.

5 Gombrich definirá la noción de paisaje al revisar sus orígenes como género pictórico institucionalizado. Ver Gombrich, E.H.Norma y forma. Estudios sobre el arte del Renacimiento. España: Alianza, 1984. Impreso.

6 Ver: Silvestri, Graciela. "Paisaje y representación." Web. 9 de marzo. Puede consultarse en: http://www.saavedrafajardo.org/Archivos/Prismas/03/Prismas03-13.pdf. También: Besse, Jean-marc. La sombra de las cosas. Sobre paisaje y geografía. Trad. Marga Neira. Madrid: Biblioteca Nueva, 2010. Impreso. 
su obra El paisaje. Génesis de un concepto, afirma: "El paisaje, en cuanto idea que representa al medio físico, es lo otro, algo que se encuentra fuera de nosotros y nos rodea, pero en cuanto constructo cultural es algo que concierne muy directamente al individuo, ya que no existe paisaje sin interpretación" (36).

Jean Luc Nancy complejizará las relaciones que existen entre el paisaje y la subjetividad. Al ser una construcción histórica, se insistirá en la presencia del sujeto que mira e interpreta, dando lugar al fenómeno identificado como paisaje. Sin embargo, también reconoce que el paisaje, al ser un reflejo del sujeto observador, paradójicamente no reproduce la imagen de su rostro. En este sentido, el sujeto implícito en todo paisaje se revela más bien como una ausencia:

We could say that landscape begins when it absorbs or dissolves all presences into itself: those of the gods or the princes, and also the presence of the peasant, at least insofar as this figure is in dialogue with those just mentioned. In the landscape, the landsman can appear, but as an element of the landscape: he is entirely given over to his occupation there, is lost in it, and that is also why he can be replaced by a traveler or a walker, in any case by figures who are occupied only with the land as such and to no other end, figures whom, by the same token, the land occupies, takes hold of and, as one says, "absorbs" into itself. (Nancy 58$)^{7}$

En El Mocho, el paisaje no solo se manifiesta en la descripción de playas y lomas costeras, sino también en la tematización de la mirada que lo posibilita. Las vistas panorámicas y parciales son generadas gracias a un sujeto que, con catalejo en mano, observa desde el parque. En efecto, el papel de observador de Arístides, el empleado de la empresa minera que está al cuidado del parque, se ve fortalecido por el uso de este instrumento óptico que delata la vasta distancia del personaje con respecto a su objeto de mirada. Al mismo tiempo, este ejercicio visual será objeto de mirada de Toño, el niño hijo del minero muerto y de Elba: "Entre los magnolios y los aromos del parque, al lado de allá en la hondonada, vi encenderse el sol ... En el parque seguía prendido el reflejo del sol en la lente del catalejo. Era don Arístides, el Mocho; yo lo sabía" (Donoso 28-29).

7 [Podríamos decir que el paisaje comienza cuando absorbe o disuelve todas las presencias dentro de sí mismo: aquellas de los dioses o de los príncipes, y también la presencia del campesino, al menos en la medida en que su figura está en diálogo con aquellas recién mencionadas. En el paisaje, el campesino puede aparecer, pero como un elemento más del paisaje: ahí él está completamente entregado a su ocupación, está perdido en ella, y de ahí que pueda ser reemplazado por un viajero o un caminante, o en cualquier caso por figuras que están ocupadas de la tierra como tal y no de otro fin, figuras de las que la tierra se apodera, ocupa y, podríamos decir, "absorbe" dentro de sí.] 
Los paisajes que a continuación revisaremos, es decir, el parque y los entornos costeros compuestos por lomas y playas, rompen la fuerte asociación entre paisaje y nación que gran parte del siglo XIX amparó en el contexto de las jóvenes repúblicas iberoamericanas:

[e]l vínculo entre paisaje y nación es, a su vez, un tópico frecuente en la visualidad y en la ensayística de siglo XIX. Desde fines del siglo precedente, viajeros, intelectuales y artistas que transitaron por la América española se valieron de la representación de la naturaleza (y de las potenciales riquezas que ésta contenía) para introducir - traducir - las nuevas naciones en el imaginario europeo (Valdés 83 ).

En Donoso, ya no se trata de una "naturaleza imaginada, devenida por tanto paisaje" (Sagredo 21) que funciona como metáfora de una "pretendida solidez institucional" (20) capaz de expresar un proyecto de nación. Más bien, el paisaje donosiano emerge desde un discurso no oficial, es decir, de la mirada testimonial ${ }^{8}$ y voyerista del bastardo que relata o de aquel que, situado en la marginalidad, se asoma al mundo de una élite social decimonónica que ya no existe, pero que dejó un paisaje a través del cual se reflejaba y confirmaba. Por ende, la mirada donosiana construye un transportador paisaje que el observador no heredó. Dados sus ambiguos orígenes sociales, Arístides, el "Mocho", desea este pasado como un valor que pudo haberle pertenecido y del cual, sin embargo, está excluido a causa de su bastardía. El mundo que Arístides tanto anhela corresponde a una de las contradictorias caras del contexto histórico del autor de Sub Terra: "Tal es el depresivo contexto nacional en el que Lillo concibe y produce su obra y que incluso lo lleva a inflexionarla. Es nuestra triste Belle Époque de pijes y de rotos, que hace florecer un jardín inglés por encima del sudor, del hollín y las llagas de los que abajo laboran" (Concha 40-41). Este contexto histórico será aludido por José Donoso en El Mocho como una irrecuperable Belle Époque gracias a la puesta en escena de una mirada impertinente: un parque que Lillo nunca mencionó y que, dadas sus condiciones paisajísticas, cita una Europa y una bella época que jamás tuvimos.

8 Leonidas Morales ha reflexionado lúcidamente sobre la relación presente entre la mirada y el discurso testimonial en la narrativa donosiana. Al respecto, ver: Morales, Leonidas. "La mirada del testigo". Novela chilena contemporánea. Fosé Donoso y Diamela Eltit. Santiago: Cuarto Propio, 2004. 55-81. Impreso. 


\section{El parque y su desmantelamiento histórico}

Diseñado por la familia Urízar para la contemplación de los yacimientos mineros, el parque permite visualizar el poder económico y el estatus de sus antiguos propietarios. La estética de tal composición paisajística evidencia, por tanto, una ideología de clase. La imitación de lo foráneo, las citas de lo exótico, el artificio compuesto por medio de una domesticación de la naturaleza y de una organización espacial, en definitiva, el efecto paisajístico que hace invisibles las condiciones materiales e históricas del mundo circundante, se desenmascaran ante la anécdota que intenta relatar y explicar el origen del parque:

Que un magnate como don Leonidas Urízar, enriquecido con el carbón de las industrias decimonónicas, convirtiera en un paraíso la península adyacente a sus minas, y lo adornara mandando construir un palacio morisco, pensando en una posible vista a los yacimientos que solventaban su boato parisino, fue la realización de un sueño muy al estilo de una época. (45)

Al presentar el parque como una excentricidad propia de un momento, la novela revela como un accidente histórico aquellas relaciones entre lo paradisíaco y el ocio que el mito había presentado como naturaleza. Como advierten Berque, Maderuelo, Serracler, entre otros teóricos del paisaje, el ocio es necesario para aquella mirada con la cual el paisaje es construido. Por el contrario, el trabajo de la tierra imposibilita esa mirada recreativa. Esta oposición es significativa en la novela, puesto que el parque, al ser metáfora de un paraíso en el que la subsistencia ya no es necesaria, establecerá una oposición con la mina, lugar del trabajo entendido como una condena infernal.

El parque, lugar en el cual el ocio es experimentado, garantiza la perspectiva y, consecuentemente, el paisaje panorámico. Bajo esta acepción, esta área verde no es en la novela El Mocho el paisaje propiamente tal, sino más bien el otro lugar que lo posibilita. ${ }^{9}$ Se trata de un "ahî" en donde la mirada se ejercita:

En la hierba de la puntilla, a la sombra de un olmo del tiempo de don Blas, extiendo mi chaqueta y me recuesto encima. Por entre las hebras de pasto veo, hacia el sur, los cerros donde se encarama el pueblo, y la caleta, y las lomas de Chivilingo; hacia el norte, desde el anfiteatro de las hortensias, vi-

9 Esta distinción entre el parque o jardín y el paisaje tiene cierta cabida y aceptación entre algunos teóricos del paisaje como, por ejemplo Javier Maderuelo (53). Berque, sin embargo, establece cuatro condiciones para poder hablar de una cultura paisajista: una palabra o más para decir "paisaje", una literatura que cante o describa la naturaleza, una representación pictórica de paisajes y, finalmente, la construcción de jardines y parques. Ver: Berque, Augustin. El pensamiento paisajero. Ed. Javier Maderuelo. Trad. Maysi Veuthey. Madrid: Biblioteca Nueva, 2009. Impreso. 
gila un prócer cuyo nombre sí recuerdo, tallado en granito plomizo, con su levita, polainas con botoncitos, mostachos y chaleco con cadena de oro. Mi padre me explicaba cada refinamiento de su indumentaria: es el patriarca, don Leonidas Urízar, el fundador de la dinastía. (Donoso 164)

Al disponer la estatua del primer Urízar como centro protagónico del jardín de hortensias, la mirada de Arístides revela su obsesión con aquella estirpe de acaudalados a la que cree pertenecer, delatando una ambigüedad social muy característica del mundo donosiano. Los orígenes obscuros de Arístides suponen una mezcla "impura" $" 10$ entre linajes aristocráticos (la familia Urízar) y linajes populares que, en la novela, están representados por las mujeres que regentan prostíbulos y circos: la María Paine Guala y la Bambina. El desclasamiento de Arístides se explicaría entonces al ser nieto de la María Paine Guala, mujer que, según las conjeturas, fue amante de don Blas Urízar, el descarriado hijo menor de Leonidas, fundador de la explotación minera. La posibilidad de descender, aunque sea bastardamente, de la potentada familia, genera en Arístides un vacío o una herida social que lo lleva a anhelar el mundo de riquezas ya pasadas, representadas en un parque que pudo haberle pertenecido.

Considerando lo anterior, la novela complejiza la estética del parque y la postura ideológica que representa al narrar sus efectos en aquellos que no pertenecen del todo a la estirpe de la acaudalada familia. En este sentido, la participación y contemplación de Arístides del parque es reveladora. El área verde deviene en un transportador lugar de ensueño y en objeto de deseo, porque nunca es suficientemente real para el sujeto desventajado socialmente: "el jardín es un paraíso laico pero no democrático" (Rojo 85).

Todo jardín, tal como lo indica la etimología de la palabra en diferentes lenguas, es un espacio cerrado o cercado. ${ }^{11}$ Separados del mundo minero no solo por el eje vertical (el parque que está arriba en oposición a las minas de abajo), sino también por sus sólidos límites, los jardines del parque dan cuenta de la desafiliación simbólica de Arístides con respecto a su clase obrera. El relato establece una oposición entre los obreros fieles a sus orígenes sociales y el desclasamiento de Arístides. Este conflicto se visualiza en la fuerza expansiva de los desechos minerales que amenazan la integridad del parque, convirtiendo a Arístides en un desterrado de

10 Ver: Eltit, Diamela. "Clases de cuerpo y cuerpos de clase". Aisthesis 38 (2005): 9-20. Impreso.

11 Con respecto al tema del jardín como lugar cercado, Nicolás Rubio y Tudurí afirma: "Las raíces indo-germánicas de la palabra 'jardín', gards, geard, garde significan cierre, espacio cercado. Algo parecido puede, dicen, opinarse de cortos, jardín o huerto en griego, que indica la idea de un terreno cercado. La palabra latina hortus, jardín, va por el mismo camino" (39). 
su amado paraíso verde: "Sí, porque con el tiempo la combustión espontánea del desecho de mineral que los obreros hemos ido excretando para beneficio de los Urízar hará avanzar el cerro hasta que arrase tu parque" (55).

Arístides y Toñito, el hijo de la Elba y del difunto minero, establecen una relación especular que se visualiza en el apego de ambos al aristocrático parque. En efecto, Elba es nieta de María Paine Huala y de don Blas Urízar. Por tanto, el niño Toño es también un descendiente ilegítimo de la familia fundadora de la explotación minera. Así como Arístides se confiesa como un "falso Urízar, un Urízar de mentira" (53-54), el niño será señalado como un sujeto extraño dentro de los que componen su clase: "Tan llorón para su edad, y mentiroso: cuenta que vive en un palacio frente al mar, con una torre tan alta, tan alta, que se asoma por encima de los magnolios" (100). El abuelo del niño confiesa acerca de su nieto "que jamás se ha visto que un hijo de obrero esté enfermo de los nervios; eso es un lujo" (101). El vínculo entrañable entre Arístides y el niño se sella en la medida en que el parque se presenta como aquel objeto común de deseo que contiene las conjeturas capaces de unirlos a la otra estirpe: "Lo que quiero es vivir en el Pabellón del parque oyéndolo a usted, don Arístides, y que me cuente cosas" (29). De este modo, cada uno de estos personajes se identifica con el otro hasta el punto que ambos serán denominados como "mochos".

Aunque Arístides es el cuidador oficial del área verde, este espacio se le irá clausurando paulatinamente, impidiéndole así el goce de su belleza y el ejercicio de una mirada paisajística:

Sube por el laberinto de calles con casas de tablones y de cemento descascarillado, hacia arriba, hacia el mar, hacia el parque: allá, por encima de las ramas, se asoma el minarete. Es hueco, porque nunca trajeron las piezas para armar la escalera de caracol que debía subir hasta el mirador de la terracita. Retarda el paso al entrar al parque: los olmos y los magnolios albergan cónclaves de pájaros que cantan mientras él da una vuelta de reconocimiento alrededor del Pabellón, buscando la puerta que usaba su padre: todas las puertas y todas las ventanas están condenadas. (163)

Las ventanas y puertas clausuradas del pabellón que está rodeado por el parque recuerdan el encierro tan característico de la poética del autor e insinúan además una inminente clausura del paisaje ante la mirada de los ojos socialmente destituidos.

En suma, el parque transita entre lo real y la fantasía. Por un lado, tiene un estatuto real al ser el lugar de trabajo de Arístides. Por otro, al mismo tiempo, el parque supone una vana ilusión con la cual el personaje es capaz de construir una historia que, en realidad, no tiene. Esta oposición es análoga 
a aquella a partir de la cual la composición novelesca se activa: el referente histórico o extratextual del Parque de Lota y el parque donosiano, es decir: esa ficción espacial que es efecto de una "referencia intratextual" (Pimentel 38). Tal vez sea poco lo que el relato "inventa": los lectores de El Mocho reconocerán aquel parque de Isidora Goyenechea de Cousiño cuya composición estuvo a cargo del paisajista inglés Mr. Bartlet y, posteriormente, del técnico irlandés Guillermo O'Reilly entre los años 1862 y 1873. Las múltiples descripciones paisajistas no agregan nada nuevo a lo que un turista puede ver o a lo que registró Francisco Marcial Aracena en sus Apuntes de viaje a finales del siglo XIX:

el parque de Lota puede mostrar hermosos bosques y jardines hábilmente ordenados, numerosos caminos, laberintos, avenidas y encrucijadas arreglados artísticamente para extraviar y divertir al visitante o al curioso a costa de sus piernas; senderos tan ocultos como poéticos a cada paso, plazuelas y cascadas; una graciosa caverna con sus pintorescos dibujos de estalactitas; puentes y estatuas de todos los tamaños y formas; quioscos y chalés, tan elegantes y admirablemente tallados unos como sencillos y construidos simplemente a la rústica otros; fuentes, maceteros. (303)

La sorpresa manierista y la inmensa variedad de flora exótica y endémica son advertidas tanto por el cronista como por el novelista, aunque el primero lo haga a partir del "modelo descriptivo del inventario" (Pimentel 174) y el segundo por medio de la anécdota. Sin embargo, lo que me gustaría recalcar es que tanto Francisco Marcial Aracena como José Donoso tienden a debilitar el estatus histórico del Parque de Lota. El viajero lo define como una "maravillosa excentricidad" (301) o como un "fantástico parque, remedo fiel a los relatos hechos al sultán por Shahrazad en los cuentos árabes de Las mil y una noches" (311). Estratégicamente, Donoso reconoce los lugares con sus nombres geográficos a excepción del parque. De este modo, el paraíso decimonónico, pintoresco, extravagante y manierista se desvincula de lo real o del referente extratextual y solo se confirma como un espejismo, una fantasía, la ilusión de un sujeto hambriento de una estética evocadora y cosmopolita. La novela genera entonces un efecto de irrealidad sobre el espacio histórico. Ese mismo efecto fue proyectado ya en el siglo XIX cuando Aracena describió un proyecto de iluminación que intentó presentar el parque como una imagen lejana e intermitente que transita entre la presencia (luz) y la ausencia (oscuridad): 
Otra obra que está por concluirse es el faro que se coloca en la punta del parque de Lota. Según informes, sabemos que será de luz blanca con destellos a intermedios de quince segundos, servido con un quemador de gas de ochenta velas, y por su altura, que es de cincuenta metros sobre el nivel del mar, se calcula que se verá a una distancia de quince millas más o menos. (281)

\section{Paisaje costero}

El mar, las playas, los cielos y las lomas serán contemplados desde diferentes puntos de vista, indicando una diversidad social. En primer lugar, apreciamos un paisaje que la Elba y Toño, los marginados del pueblo que habitan una improvisada choza, miran desde abajo, es decir, desde la playa:

Ven dibujarse sobre las ramas del parque, allá lejos, hacia el norte, el minarete que agracia el Pabellón. Más acá, el larguísimo ciempiés del muelle se estira sobre el océano. A esta hora queda oculta hacia el norte, entre la península del parque y la colina de escoria excretada por un siglo de explotación de la mina, la hondonada donde están viviendo: la colina de tosca se desplaza lenta y tibia, como el cuerpo de un dragón resbaloso cuyos vapores enredan los fierros de las maestranzas y esa gigantesca polea que permite bajar el ascensor con cien hombres hasta el fondo de la mina, en un entrevero de fierros negros y cintas y escaleras y enormes ruedas, como la silueta de un Luna Park de pesadilla. (33)

Cabe destacar que este paisaje supone un quiebre social: el parque ubicado en la parte superior de la península contrasta con la hondonada en la que viven la madre y el niño, lugar próximo a una colina descrita como un dragón monstruoso que devora las instalaciones de la mina.

Desde un ángulo social opuesto, un paisaje marino guarda relación con la mirada de los descendientes de Leonidas Urízar, el fundador de la explotación minera:

No valía la pena emprender un viaje de tanto esfuerzo, suspiraron ellas, con el único propósito de darle a papá el gusto de ir a apoyarse en la balaustrada de falsos troncos que circunda la glorieta, para contemplar los ocasos nacionales sobre un océano que, por muy inmenso que fuera, quedaba realmente demasiado a trasmano. (46)

Se trata de una aproximación visual foránea y distante, ya que los descendientes del fundador son criollos radicados en Europa. Se podría hablar incluso de un paisaje europeizante y cosmopolita. Además, la descripción recién citada 
acusa ciertos signos que hablan de una imitación periférica de las modas europeas. Ejemplo de ello es la falsedad de la balaustrada, elemento decorativo y límite del lugar desde donde se contempla.

La ambigua posición de Arístides sintetiza la diversidad social de los dos paisajes recientemente identificados. El paisaje que Arístides intenta construir no solo explicita las ocultas conexiones existentes entre el mundo de lo popular y el mundo de una élite social, sino que también devela aquello que solo el otro puede ver en el espacio que le es constitutivamente ajeno. En otras palabras, las descripciones paisajísticas puestas en boca de Arístides están sujetas a una experiencia de extrañamiento tal que ilumina todo aquello que, por sernos tal vez demasiado familiar, habría aparecido de manera un tanto desmaterializada.

Pese a la diversidad social aludida, los paisajes que dibujan los entornos de Lota están motivados por una inquietud estética común a la mayoría de los personajes independientemente de su condición: "Mira, hijo, le dice la Elba a Toño, señalando el horizonte: va a comenzar a oscurecer. Y calla. El pueblo sobre los cerros comienza a iluminarse" (33). Lo anterior señala el carácter comunitario de un paisaje que se presenta como apreciación comunicable y, por tanto, compartible con los demás. En este sentido, la novela marca una oposición entre el parque, propiedad de la empresa minera, y los entornos de Lota, sujetos a una apropiación popular. Hay un pasaje de la novela que es muy revelador al respecto. El Mocho reconoce en las nubes del cielo peces de vivos colores:

Un día el Mocho tiene una sensación mágica: señalando el cielo con un dedo, sigue la dirección de las nubes, del viento y del frío. Dice que miren, no se lo pierdan, el cielo está precioso, lleno de pescados plateados que navegan por el azul, agitando sus colas en el aire y luciendo entre las nubes la platería de sus escamas ... Nadie le creyó ni una palabra al Mocho ... Pero era hermoso contemplar los atardeceres de invierno aunque nadie hasta ahora hubiera hablado jamás de los jureles que navegaban por el cielo. (200)

El ejercicio visual del Mocho convierte el cielo en mar y, de paso, nos recuerda las recomendaciones de Leonardo da Vinci a sus discípulos, escritas en su Tratado de la pintura. En efecto, el maestro del Quatrocento aconsejaba "mirar algo y ver otra cosa" (Cirlot 31) para así estimular el ingenio y la invención. ${ }^{12}$ En

12 En la traducción castellana de Diego Antonio Rejón de Silva (1784), Leonardo se expresa de la siguiente manera: "y es, que cuando veas alguna pared manchada en muchas partes, ó algunas piedras jaspeadas, podrás mirándolas con cuidado y atención advertir la invención y semejanza de algunos países, batallas, actitudes prontas de figuras, fisonomías extrañas, ropas 
este juego visual del Mocho participarán finalmente las mujeres del prostíbulo de la Bambina, gestándose una comunidad en torno al cielo y sus nubes:

Esta vez, sin embargo, al mirar, más de alguien le creyó al Mocho. ¿Qué no veían las nubes puntiagudas, las aletas agitadas, los ojos brillando, traficando entre las nubes? Los jureles eran comida, la de todos los días, fritanga o caldillo, y no materia de fantasía. Las chiquillas de la casa estaban entreteniéndose con las nubes que eran pescados. (Donoso 201)

La novela propone también un paisaje comunitario al describir un cementerio paradójicamente vacío cuya visión generaría lazos de empatía entre los lugareños. En efecto, la obra comienza con un relato de orfandad y de escritura. Tras la muerte de su padre, cuyo cuerpo se ha extraviado, Toño, el niño, simula un ritual fúnebre, colocando las pertenencias de su progenitor en una caja para finalmente escribir sobre esta su nombre:

Fue metiendo la ropa vieja de su padre en una caja que encontró en el basural: pantalones rajados, calcetines huachos, una camiseta tiznada, un gorro de lana,junto a sus documentos de identidad y la foto donde abrazaba a la Elba en la plaza de Lebu, tomada poco antes de que él naciera. . . Y con azarcón escribió en la tapa y en el rótulo, con una cruz, Antonio Alvayay Medina, que era el nombre del padre. (Donoso 17)

La desaparición del cuerpo en la mina intensifica en el niño el sentimiento de orfandad, porque el recuerdo se ve amenazado por esta doble ausencia, vale decir: la de la vida del padre y, además, la de sus restos. Para Toño, la mina se transforma en un mundo de tinieblas por cuya causa los sentidos se atrofian y la imaginación se vuelve incapaz de dibujar un retrato del ausente:

El niño piensa, mientras busca más cosas que echar en su caja insaciable, que quedar sepultado en el fondo del Pique Grande con los otros cinco barreteros muertos no es lo mismo que quedar sepultado con su nombre y una crucecita de madera en un lugar definido. No busques más, Toño. Pero buscas y buscas porque tienes terror de que tu pensamiento no alcance a tocar a tu padre, a mi marido, en las tinieblas de la mina. Igual a los hijos de los pescadores que no podían encontrar el cuerpo del padre desaparecido en el mar, tan hondo y tan incierto y de noche tan oscuro como la mina. (18)

particulares y otras infinitas cosas; porque de semejantes confusiones es de donde el ingenio saca nuevas invenciones" (citado en Cirlot 31-32). 
Este paisaje se constituye a partir de la ausencia que se expresa, no necesariamente desde una crítica social dirigida a las condiciones desfavorables del trabajador, sino más bien desde la alusión a los detenidos desaparecidos durante la dictadura militar en Chile. Las víctimas del régimen se disfrazan de trabajadores para integrarse a la simulación del ritual fúnebre celebrado por el niño huérfano: "Pero fue Toño el que dijo, como si fuera comunista: ¿por qué no va a ser una buena manera de sepultar también a los desaparecidos en otras desgracias, como los que perdieron la vida debajo de toneladas de escoria en el derrumbe de una mina?" (19). A esto debe sumarse que el funeral de ataúdes vacíos se transforma en una romería política de protesta que camina hacia el cementerio.

$\mathrm{Al}$ ser escrito sobre la tierra, el nombre del difunto padre tiene simbólicamente el poder de recuperar el cuerpo desaparecido y de sepultarlo. El entierro figurado del minero y la consecuente composición del paisaje como cementerio refuerzan los lazos comunitarios del pueblo:

Pero cuando alguien suba las lomas de Chivilingo que miran hacia la bahía de Arauco por encima del pinar, verá las tumbas polvorientas con sus cercos de palitos blancos o malva en los cerros pelados, y cuando lea el letrero que pintó Toño y vuelva a bajar al pueblo, podrá decirle cuando se encuentre con él: -Oye, vi la tumba donde pusieron a tu papá, Toñito. (19)

Finalmente, una descripción al modo de una ekphrásis consuma este paisaje que ha generado el diálogo y el reconocimiento de los lugareños entre sí:

Arriba se encontraron con las conocidas tumbas vacías, que no contenían cuerpo alguno, pero con una cruz que rememoraba a un amigo, o un nombre que reconocieron. También examinaron la crucecita de madera pintada color verde mar que la Elba había plantado allí después de la muerte de Antonio. Pero sucedió lo que a menudo sucede en la costa: uno se queda dos minutos con la vista fija en los cerros del interior y el secarral, observando los campos desolados, y pocos minutos después se da vuelta hacia el mar otra vez y se encuentra que todo está luminoso, verde, plateado. (208)

\section{Conclusiones}

Más que como un paisaje, el huerto-jardín en el cuento de Baldomero Lillo fue identificado como una parcela de utopía moderna en la cual el sujeto se soñaba y construía, rompiendo, al menos como una ilusión, las determinaciones ambientales. El parque donosiano, en cambio, se dibuja como un paisaje en el cual el sujeto, desde el punto de vista de la clase social, se disloca 
y fragmenta, poniendo en jaque su visibilidad y su identificación unívoca. "¿Cómo hablar y, en lugar de hacerse presente, más bien desaparecer haciéndolo?" (Manrique 4): esta pregunta, con la cual Carlos Manrique da inicio a su estudio sobre Foucault titulado "La palabra transgresiva y la otra vida", puede iluminar el problema que supone la relación sujeto/paisaje en José Donoso. ${ }^{13}$ El paisaje, tal como lo hemos afirmado, es una construcción cultural que necesariamente sitúa al sujeto. La descripción paisajística donosiana, sin embargo, es un lenguaje que conlleva un efecto contrario: un cuerpo desdibujado en los cruces de clases sociales que suspenden la sujeción del observador paisajístico a un orden; la irrupción de una oscuridad que hace del paisaje una visión transitoria y fragmentada que no alcanza a ser garantía de una subjetividad. Como género, el paisaje sintetiza el espacio y el lenguaje, porque podría ser definido medularmente como la representación de un paraje sujeto a ciertas convenciones. En Donoso, se trataría más bien de un lenguaje que produce un espacio en el cual la subjetividad ya no se reconoce, al menos, por la presencia. En suma, el relato de José Donoso no arroja la imagen de un sujeto que podríamos comprender bajo el amparo o sustento de una esencia. Y el paisaje es una confirmación de ese vacío.

13 Reproducimos un pasaje del artículo de Carlos Manrique en el que explica la borradura de la subjetividad precisamente en aquel espacio que es la misma escritura: "En uno de los textos escrito a manera de comentario y de tributo a la obra de Blanchot, el acento de la reflexión insiste en señalar cómo esta peculiar experiencia del lenguaje que es también una cierta experiencia de pensamiento se da, y se hace efectiva, precisamente en la desaparición, la borradura del sujeto que enuncia el discurso, el sujeto que habla, o más bien, se escribe. Borradura del sujeto hablante en la que no es tanto 'la realidad' del lenguaje lo que se manifiesta, sino también un cierto silencio, un cierto vacío, un cierto espacio o espaciamiento que socava su 'ser"' (Manrique 24). 


\section{Obras citadas}

Aracena, Francisco Marcial. "Lota, el famoso parque de la señora doña Isidora g.v. de Cousiño". Apuntes de viaje: la industria del cobre en las provincias de atacama y Coquimbo, los grandes y valiosos depósitos carboníferos de lota y Coronel en la provincia de Concepción (1878-1883). Santiago: Cámara Chilena de la Construcción, 2011. 301-316. Impreso.

Cirlot, Victoria. "II. La polvareda, los ejércitos y la mancha en la pared." La visión abierta. Del mito del Grial al surrealismo. España: Siruela, 2010. 29-42. Impreso.

Concha, Jaime. "Lillo y los condenados de la tierra". Introducción. Obra completa por Baldomero Lillo. Ed. Ignacio Álvarez y Hugo Bello. Santiago: Ediciones Universidad Alberto Hurtado, 2008. 17-67. Impreso.

Donoso, José. El Mocho. Chile: Punto de Lectura, 2004. Impreso.

Donoso, Pilar. Correr el tupido velo. Santiago: Alfaguara, 2009. Impreso.

Espinosa, Patricia. "La visualización del otro, como parte del proceso de construcción de la identidad en Sub Terra de Baldomero Lillo". Aisthesis 34 (2001): 125-33. Impreso.

Fonseca, Francisca. "Procesos de ruptura y continuidad entre naturaleza y sociedad en la ciudad moderna". Papers 88 (2008): 141-51. Impreso.

Franz, Carlos. "Donoso, final abierto". Letras.s5.com. Web. 6 de marzo de 2014.

Goic, Cedomil. La Novela Chilena. Los Mitos Degradados. Santiago: Universitaria, 1997. Impreso.

Lázaro Carreter, Fernando. Diccionario de Términos Filológicos. Madrid: Gredos, 1973. Impreso.

Lillo, Baldomero. Obra Completa. Ed. Ignacio Álvarez y Hugo Bello. Santiago: Ediciones Universidad Alberto Hurtado, 2008. Impreso.

Lotman, Yuri M. Estructura del Texto Artístico. Trad. Victoriano Imbert. España: Ediciones Istmo, 1982. Impreso.

Maderuelo, Javier. El paisaje. Génesis de un concepto. Madrid: Abada, 2006. Impreso.

Manrique, Carlos. "La palabra transgresiva y la otra vida". Revista de Estudios Sociales 43 (2012): 23-35. Impreso.

Martínez, Juana. "El cuento hispanoamericano del siglo XIX". Historia de la Literatura Hispanoamericana. Tomo II. Del Neoclasicismo al Modernismo. Coord. Luis Íñigo Madrigal. Madrid: Cátedra, 1993. Impreso.

Montes, Hugo. Historia y Antología de la Literatura Chilena. Santiago: Zig-Zag, 1965. Impreso.

Nancy, Jean Luc. "Uncanny landscape". The ground of the image. Trad. Jeff Fort. Nueva York: Fordham University Press, 2005. 51-62. Impreso. 
Pimentel, Luz Aurora. El espacio en la ficción. La representación del espacio en los textos narrativos. México: Siglo XXI, 2010. Impreso.

Rojo, José Tito. "El paraíso es un jardín". Fardín y paisaje. Miradas cruzadas. Eds. Juan Calatrava y José Tito. Madrid: Abada, 2011. 71-85. Impreso.

Rubio y Tudurí, Nicolás. Del paraíso al jardín latino: origen y formación del jardín latino. Barcelona: Tusquets, 1981. Impreso.

Sagredo, Rafael. "Prefacio. Un paisaje inquietante". Una geografía imaginada. Diez ensayos sobre arte y naturaleza. Santiago: Metales Pesados, 2014. 19-22. Impreso.

Valdés, Catalina. "Comienzo y deriva de la pintura de paisaje chilena". Una geografía imaginada. Diez ensayos sobre arte y naturaleza.

Santiago: Metales Pesados, 2014. 83-111. Impreso. 